\title{
Transformaciones, conflictos e identidades en el Centro Histórico de Salvador de Bahia
}

\author{
Emilio José LuQue AzConA \\ Universidad de Sevilla \\ eluque1@us.es \\ Harry SMITH \\ Heriot Watt University, Reino Unido \\ H.C.Smith@sbe.hw.ac.uk
}

Recepción: 1 de abril de 2009 / Revisión: 5 de octubre de 2009

Aceptación: 16 de octubre de 2009 / Publicación: diciembre de 2010

\begin{abstract}
RESUMEN
Poco después de su nombramiento como Patrimonio Mundial por la UNESCO en 1985, el Centro Histórico de Salvador de Bahia, y más concretamente el Pelourinho, comenzó a experimentar importantes transformaciones encaminadas a consolidar a esta ciudad brasileña como un destacado referente turístico de América del Sur. Los resultados de las políticas de intervención llevadas a cabo en este sentido han despertado sentimientos encontrados entre los diferentes actores involucrados en el proceso, al tiempo que han servido como referente para otras ciudades que, de manera parecida a Salvador, han visto en sus respectivas áreas centrales antiguas un importante potencial para el desarrollo del turismo. En el presente artículo se analizan las diferentes políticas de intervención que las autoridades locales y regionales han llevado a cabo en el Centro Histórico de Salvador desde fines del siglo XIX. Con ello queremos poner de relieve las sucesivas "reinvenciones" y transformaciones que la zona ha experimentado, respondiendo, por lo general, a los diferentes intereses de los grupos de poder que las impulsaron. También se destacan algunos de los conflictos generados a lo largo de dicho proceso y los retos pendientes para la conformación del Pelourinho en un espacio vivo y multifuncional.
\end{abstract}

Palabras clave: bien cultural, Brasil, ciudad, centros históricos, políticas urbanas, Salvador de Bahía, siglo XX.

\section{Transformation, conflict and identities in the historic centre of Salvador de Bahia}

\begin{abstract}
Shortly after its designation as a World Heritage Site by UNESCO in 1985, the historic centre of Salvador de Bahia, and more specifically Pelourinho, started to undergo significant changes which were oriented to the consolidation of this Brazilian city as an important tourist destination in South America. The outcome of the regeneration policies that have been implemented to this end has elicited conflicting reactions among the stakeholders in the process and the results have become points of reference for other cities which have identified the potential for tourism in their central historic areas, as in Salvador. This paper analyses the various urban renewal policies that local and regional authorities have implemented in the historic centre of Salvador since the late nineteenth century. In doing so we wish to highlight the successive 'reinventions' and transformations of the area, which in general have responded to the interests of the power groups that initiated them. In addition, the paper focuses on some of the conflicts which arose during the process, as well as the challenges that remain in order to turn Pelourinho into a lively, multifunctional space.
\end{abstract}


Keywords: Brazil, Cities, Cultural Property, Historic Centres, Urban Policy, Salvador de Bahia, 20th Century.

SUMARIO: 1. Introducción. 2. Evolución histórica de la ciudad de Salvador hasta fines del siglo XIX. 3. Políticas urbanas y reinvenciones. 3.1 Primera fase: "civilizar" y modernizar Salvador. 3.2 Segunda fase: el patrimonio como recurso para la conformación de la identidad nacional brasileña. 3.3 Tercera fase: construir una nueva Bahia "respetando su pasado". 3.4 Cuarta fase: el turismo como motor para el cambio. 4. Reflexiones finales. 5. Referencias bibliográficas.

\section{INTRODUCCIÓN}

La zona del Pelourinho, localizada en el Centro Histórico de Salvador de Bahia, constituye en la actualidad uno de los principales referentes con los que cuenta Brasil de cara a la promoción del turismo. Sus calles y plazas empedradas, llenas de comercios y museos, junto con la majestuosidad de sus coloridos edificios coloniales y la existencia de una agitada agenda de espectáculos culturales, atraen cada año a un importante volumen de turistas que llegan, por lo general, dispuestos a disfrutar de las paradisíacas playas del litoral bahiano.

La situación actual que presenta el Pelourinho responde, en buena medida, a las políticas aplicadas a partir del año 1990 con el objetivo de fomentar el turismo en la zona. Éstas han recibido numerosas críticas por convertir las áreas intervenidas en una especie de parque temático para turistas, tras la idealización del espacio urbano y arquitectónico y la expulsión de gran parte de su tradicional vecindario. De hecho, el Pelourinho constituye en la actualidad uno de los ejemplos más paradigmáticos de "musealización" urbana. Es por ello por lo que, de manera parecida a otras Ciudades Patrimonio de la Humanidad, Salvador continúa teniendo ante sí el gran reto de aprovechar las oportunidades que ofrece su rico legado patrimonial para impulsar procesos sostenibles de recuperación urbana integral, canalizando el turismo en función de las exigencias de la conservación y de las necesidades y deseos que se derivan de lo local ${ }^{1}$.

En este sentido, para el caso de Salvador, pese a las numerosas problemáticas económicas y sociales que padece la ciudad y la región en la que se inserta, varios elementos nos permiten ser optimistas de cara a la consecución del gran reto mencionado. Por una parte, las autoridades encargadas de gestionar el Centro Histórico de la ciudad han tratado en los últimos años de corregir algunas de las medidas adoptadas previamente, conscientes de la inviabilidad del modelo que desembocó en la citada musealización del Pelourinho y en una dependencia excesiva de la actividad turística para su sostenimiento económico. Por otro lado, a diferencia de lo sucedido en otras ciudades que, de manera parecida a Salvador, han visto también en sus respectivos centros/cascos históricos lugares privilegiados para el diseño de estrategias orientadas a la atracción de inversiones y visitantes, en Salvador no se ha producido el proceso que el geógrafo David Harvey denomina "mercantilización multinacional homogeneizadora"2. Es decir, más allá de esa "disneyficación" del paisaje, en el Pelourinho no se han instalado prácticamente establecimientos multinacionales, aspecto que ha contribuido en otros centros/cascos históricos a la pérdida de la sin-

1 Troitiño VinUesa, 2009, p. 19.

2 Harvey, 2007, p. 430. 
gularidad que sirvió en los inicios como reclamo para la atracción de turistas, nuevos residentes y negocios. Tampoco ha habido un fenómeno de "gentrificación"3 que haya convertido a la zona en lugar de residencia exclusivo de sectores con elevado poder adquisitivo, como ha sucedido de manera particular en ciudades de Europa ${ }^{4}$. Entre las causas de ello se encuentra, principalmente, el escaso interés del capital privado por invertir en el Centro Histórico de Salvador, como mencionaremos más adelante.

Con el objetivo de contribuir a los debates existentes entre los especialistas de diferentes disciplinas implicadas en el estudio y la gestión del Pelourinho, nos pareció importante realizar un aporte desde la disciplina de la Historia. Concretamente mostrando que las intervenciones realizadas en la zona a partir de 1990 son una fase más de las distintas actuaciones que, desde fines del siglo XIX, han experimentado diferentes zonas del Centro Histórico de Salvador. Con ello quisimos poner de relieve que, con objetivos diferentes, todas estas actuaciones han causado, en mayor o menor medida, transformaciones drásticas en el plano urbano, arquitectónico y funcional del área central antigua de la ciudad, que responden a los intereses de los grupos de poder que las impulsaron. El análisis de este largo proceso, que arranca a fines del siglo XIX y abarca hasta la actualidad, aporta, sin duda, una base sólida desde la que poder proyectar los posibles cambios de cara a una nueva fase de intervención en el Pelourinho, que evite los errores cometidos en el pasado.

La idea de desarrollar esta investigación surgió a partir de una visita realizada a Salvador en agosto de 2004, durante la cual tuvimos ocasión de comprobar los numerosos problemas que afectan a su centro histórico. A partir de ese momento empezamos a analizar el abundante material bibliográfico que, desde distintas disciplinas, analiza diferentes cuestiones relacionadas con la gestión y la situación vivida por el Pelourinho durante las últimas décadas. También, junto a legislación relativa a la gestión del patrimonio en Brasil, hemos consultado estudios de carácter histórico, con el objetivo de comprender la evolución de la ciudad de Salvador desde su fundación en 1549, obras literarias que describen la situación del Pelourinho durante la primera mitad del siglo XX, y artículos de prensa que aparecen reproducidos, pero no analizados, en una obra citada en este trabajo, cuyo autor es Rodrigo Melo Franco de Andrade. Por otra parte, hemos consultado fuentes cartográficas, que se reproducen también en las obras citadas en la bibliografía, como las de Adriana Almeida Couto o Nestor Goulart Reis, e intercambiado opiniones con especialistas implicados en estos debates 5 .

${ }^{3}$ El término de "gentrificación", que alude a la sustitución de población de escasos recursos por otra de mayor nivel adquisitivo en los centros de las ciudades, procede de la palabra inglesa gentrification y fue empleado por primera vez por Ruth Glass, en su trabajo titulado London, aspects of change, publicado en Londres en 1964. Para una mayor profundización sobre el concepto de gentrificación, consultar SARGATAL BATALLER, 2000.

4 Para un proceso comparativo de experiencias de intervención en centros/cascos históricos de Europa y América Latina consultar LuQue AZCONA - SMITH, 2007.

5 En este sentido, queremos agradecer a la doctora Silvia Helena Zanirato, de la Universidade Estadual de Maringa, el asesoramiento recibido para la realización de la presente investigación. 


\section{EVOLUCIÓN HISTÓRICA DE LA CIUDAD DE SALVADOR HASTA FINES DEL SIGLO XIX}

El análisis de las diferentes medidas de intervención realizadas desde fines del siglo XIX en lo que después conformaría el Centro Histórico de Salvador requiere de un análisis previo que permita comprender el origen de algunas de las características urbanísticas, arquitectónicas y funcionales presentadas por dicha zona en el momento en el que comenzaron a ponerse en práctica las reformas que abordaremos en el siguiente apartado.

Salvador se fundó como sede del Gobierno General de Brasil en el año 1549, en el marco de los procesos colonizadores desarrollados por los portugueses en diferentes puntos de la fachada atlántica del continente sudamericano. Consolidada como la perla de la Corona de Portugal en América, fue la ciudad más relevante que tuvo el Brasil colonial, región en la que lo urbano contó con una presencia costera y puntual hasta bien avanzado el siglo XVIII 6 .

Para la fundación de Salvador se escogió un enclave estratégico situado junto a una amplia bahía, prácticamente a medio camino entre los límites norte y sur de Brasil, bautizada con el nombre de Todos los Santos y localizada dentro de la región de tierras húmedas y cálidas que recibe el nombre de recôncavo. La ciudad se estableció concretamente a la entrada de la mencionada bahía, en el extremo sur de una península en forma de "V" cuyo brazo derecho se orienta al océano Atlántico. Desde sus inicios estuvo dividida por un profundo risco que separa la Cidade Alta, convertida en centro político, administrativo, religioso y residencial, de la Cidade Baixa, lugar en el que comenzaron a desarrollarse las actividades portuarias y las asociadas a ella, como era común en otros núcleos de población portugueses 7 .

Consolidada pronto como el principal enclave comercial, a través de su puerto se exportaron diferentes productos con gran demanda internacional, como el azúcar desde el siglo XVI, o el tabaco a partir del siglo XVII. El traslado de la capital del Virreinato del Brasil a Río de Janeiro en 1763 no impidió que la ciudad siguiera desarrollando sus actividades comerciales y portuarias, gracias al crecimiento de la agricultura y el descubrimiento de oro y diamantes al norte de Minas y en la Chapada Diamantina de Bahia. A lo largo de los siglos XVIII y XIX, el algodón, el cuero, el oro y los diamantes fueron sus principales exportaciones. Asimismo, Salvador fue durante mucho tiempo el único punto de importación de productos manufacturados desde Portugal, y el mayor mercado de esclavos africanos del Brasil ${ }^{8}$.

Entre fines del siglo XVI e inicios de la década de 1760, la población de Salvador se multiplicó por cinco, pasando de 8.000 a 40.000 habitantes $^{9}$. La ciudad, como era común en la época, se caracterizó por la existencia de una rígida división social entre su población. Los sectores privilegiados estaban conformados por comerciantes, personal administrativo, alto clero secular y regular, por lo general de origen portugués,

\footnotetext{
6 GuTIÉrRez, 1997, p. 69; ROMERo, 1986, p. 12.

7 Gutiérrez, 1997, p. 100; Petti Pinheiro, 2002, p. 182.

8 Almeida Couto, 2000, pp. 17, 20 y 24.

9 GutiérREZ, 1997, p. 99.
} 
y los señores de los ingenios de azúcar ${ }^{10}$. Estos tendieron a concentrarse en zonas como la del Pelourinho a lo largo del siglo XVIII, que comprende, grosso modo, el área de ocupación más antigua de la Cidade Alta.

El grupo más numeroso, el de los no privilegiados, lo integraban desocupados, mendigos y esclavos, en su mayoría de origen africano. De estos últimos dependían aspectos tan vitales como el abastecimiento de alimentos y agua, el transporte o la eliminación de los desechos ${ }^{11}$. Lo más común durante el período colonial fue que los diferentes sectores de la población convivieran compartiendo un mismo espacio urbano, siendo la presencia de personas de origen africano mayoritaria en las calles y plazas de Salvador. Este hecho llegó a generar en los sectores más privilegiados cierto sentimiento de inseguridad ante posibles revueltas ${ }^{12}$.

La pujanza económica vivida por Salvador durante el período colonial permitió que la ciudad consolidara pronto un relevante paisaje urbano y arquitectónico. La Cidade Alta, en concreto, se proyectó sobre un suelo montañoso irregular con un trazado en cuadrícula y calles ortogonales adaptadas al relieve de la zona ${ }^{13}$. El peligro de ataques que pudieran protagonizar tanto potencias enemigas como la población indígena regional obligó desde fechas tempranas al desarrollo de obras para la defensa de la ciudad ${ }^{14}$. Entre los espacios públicos que se conformaron en la Cidade Alta destacaron algunos como la plaza do Palacio, que albergó edificios significativos, como el Palácio dos Governadores o el Terreiro de Jesus, en torno al cual se construyeron viviendas, suntuosos templos y el Colegio de Jesús de Salvador ${ }^{15}$. Tras la demolición del castelo das Portas do Carmo, en la década de 1780, se conformaría el largo ${ }^{16}$ que más tarde recibió el nombre del Pelourinho, por la instalación en 1807, frente a la Iglesia de Nossa Señora dos Rosarios dos Pretos, de un pelourinho o tronco para castigo de los esclavos ${ }^{17}$.

Hasta comienzos del siglo XVIII hubo en Salvador una transferencia cultural directa desde Portugal, aspecto que propició la existencia en las obras arquitectónicas iniciales de rasgos de fidelidad con la arquitectura lusitana ${ }^{18}$. En la centuria anterior, Bahia se había consolidado como uno de los principales focos en los que el Barroco iberoamericano alcanzó mayor desarrollo, siendo precisamente con ese nuevo lenguaje que Salvador conformó, entre fines del siglo XVII e inicios del siglo XVIII, la mayor parte de los monumentos arquitectónicos que hoy posee su centro histórico. La riqueza generada por la actividad comercial durante la segunda mitad

10 Olszewski Filha, 1989, p. 16.

11 Almeida couto, 2000, p. 24.

12 Petti Pinheiro, 2002, p. 93.

13 Goulart Reis, 2001, pp. 16, 17, 27 y 31.

14 Ibídem, pp. 27, 30, 32-34.

15 Almeida Couto, 2000, p. 69.

16 En el caso portugués, el largo fue, junto a la plaza, un elemento destacado en la trama urbana de las ciudades. El primero como "calle ensanchada a la que se asignaban funciones comerciales y eventualmente de mercado" y la segunda como "espacio residual que se dotaba con ciertas funciones". GUTIÉRREZ, 1997, p. 100.

17 ANDRADE, 2004, p. 74

18 GuTIÉRREZ, 1997, p. 69. 
del siglo XVIII, junto con el desarrollo de las corporaciones gremiales, las hermandades y cofradías, y las órdenes terceras de laicos adscritos a los conventos, fomentaron la proliferación de edificios religiosos en la trama urbana, ocasionándose con ello un fuerte impacto en su paisaje arquitectónico por las dimensiones y la monumentalidad con las que se les dotón ${ }^{19}$.

Durante el siglo XIX, diversos factores llevaron a Salvador a perder el papel de primer orden desempeñado hasta entonces a nivel continental, al ver reducida de forma drástica su área de influencia. La huida de comerciantes portugueses tras la independencia de Brasil en 1822, la subida del precio del algodón, la cotización del azúcar o la prohibición del tráfico de esclavos en 1850, treinta y ocho años antes de la abolición definitiva de la esclavitud, obligaron al replanteamiento del sector productivo local. Este pasó a orientarse, a partir de entonces, hacia el desarrollo del sector industrial o manufacturero, mediante la producción de bebidas, alimentos, velas, cigarros y tejidos ${ }^{20}$. No obstante, la mala respuesta del mercado externo e interno, y la competencia que supuso el crecimiento del sector secundario en la región centrosur de Brasil, ante la que Salvador no podía competir, hicieron mella en la economía de una ciudad que vio con ello reducido su peso. No obstante, su integración en la estructura capitalista internacional como puerto de ámbito regional permitió cierto dinamismo económico y abrió las posibilidades a la llegada de inversiones de capital extranjero a la ciudad ${ }^{21}$.

\section{POLÍTICAS URBANAS Y REINVENCIONES}

En el presente apartado vamos a analizar las diferentes fases de intervención desarrolladas en el área central antigua de Salvador desde fines del siglo XIX. Cada una de ellas, como decíamos en la introducción, ha respondido a diferentes objetivos y ha ocasionado importantes transformaciones en la zona, tanto a nivel paisajístico como funcional.

\subsection{Primera fase: “civilizar” y modernizar Salvador}

Salvador experimentó importantes transformaciones en el terreno urbanístico a lo largo de la segunda mitad del siglo XIX, especialmente en la Cidade Baixa, al proyectarse en la zona, junto a la modernización del puerto, un conjunto urbano con trazado regular conformado por edificaciones homogéneas en altura y aspecto exterior. Este tipo de actuaciones respondieron al ideario de la burguesía comercial. Por otra parte, en la Cidade Alta, el centro político, administrativo y religioso de Sé, concretamente la zona comprendida entre la Praça do Palácio y el Largo do Teatro, fue la que experimentó mayores cambios con la transformación de la estructura urbana preexistente, el derribo de viejas edificaciones y la introducción de nuevos servicios de

19 Ibidem, p. 202 y TAVARES, 1987, p. 73.

20 Almeida Couto, 2000, p. 29.

21 Petti Pinheiro, 2002, pp. 198 y 203. 
infraestructura. Un importante avance para Salvador en esos momentos fue la mejora de las comunicaciones entre la parte alta y baja de la ciudad, para lo cual se construyó una vía de tránsito, conocida como la Ladeira da Montanha, y se inauguraron dos elevadores hidráulicos, que permitieron un tráfico más fluido de personas y mercancías. Mediante el impulso de medidas de este tipo, las autoridades modernizar Salvador y su inclusión entre las ciudades "civilizadas" del mundo ${ }^{22}$.

Con este objetivo, a lo largo de dicha centuria se produjeron también mejoras en determinados servicios, sobre todo a partir de la abolición definitiva de la esclavitud, hecho que obligó a la introducción de nuevas tecnologías para el abastecimiento de agua, la iluminación a gas o el transporte. El último propició, a partir de 1860, un crecimiento considerable de la trama urbana de la ciudad y el inicio del proceso de segregación espacial, al permitir la mudanza de los sectores más acomodados desde el centro hacia los nuevos barrios que comenzaron a conformarse hacia el sur, como los de Vitória, Canela, Graça y Barra ${ }^{23}$. De manera paralela, junto a los sectores medios que permanecieron en el Pelourinho, comenzó a instalarse en esos momentos una población de escasos recursos, compuesta en su mayor parte por inmigrantes que llegaban a Salvador tras la abolición de la esclavitud en 1888, o escapando de la crisis desatada en el campo tras una prolongada falta de lluvias 24 .

Las reformas urbanas orientadas a la modernización de Salvador continuaron desarrollándose durante las primeras décadas del siglo XX. Éstas experimentaron un mayor impulso durante el gobierno de José Joaquín Seabra (1912-1916), al darse en esos momentos la coyuntura política y económica favorable para que ello se produjese. Dicho gobernante, que había sido ministro en Rio de Janeiro previamente y testigo de las reformas urbanas desarrolladas en dicha ciudad, contó para su proyecto con el apoyo federal y municipal, y con capitales nacionales y extranjeros. De manera parecida a lo sucedido en otras ciudades europeas, norteamericanas e iberoamericanas de la época, estas intervenciones urbanas se vieron impulsadas por el deseo de dar respuesta a problemas de higiene urbana y por la necesidad de adaptar la trama urbana a los avances producidos en los sistemas de transporte, los cambios en el plano funcional y la segregación social. Al mismo tiempo, también hubo razones de índole estético que buscaron transformar los vestigios del pasado colonial de Salvador en una imagen europea y, más concretamente, parisina ${ }^{25}$.

Como consecuencia de todo ello, se procedió al embellecimiento de largos y plazas, a la apertura de nuevas avenidas, caso de la Sete de Setembro, y al ensanchamiento y ampliación de calles ya existentes. Todo ello requirió de la demolición de importantes conjuntos arquitectónicos, entre los que estuvieron la Iglesia de São Pedro Velho o parte de los edificios del Senado do Estado, la Iglesia do Rosário de João Pereira y el Convento das Mercês, aspecto éste que la prensa de la época justificó como forma de lograr la tan ansiada modernización de la ciudad. Junto a las

22 Ibídem, pp. 210-219.

23 Almeida Couto, 2000, pp. 31 y 32; Mattos, 1978, p. 26; Petti Pinheiro, 2002, p. 206.

24 Andrade, 2004, p. 74; Olszewski Filha, 1989, p. 27; Petti Pinheiro, 2002, pp. 187, 193 y 194.

25 Petti Pinheiro, 2002, pp. 219-255. 
demoliciones, el paisaje arquitectónico también experimentó importantes transformaciones mediante la introducción del lenguaje arquitectónico ecléctico, visto por entonces como símbolo de progreso e imagen republicana del Brasil moderno ${ }^{26}$.

Las intervenciones desarrolladas en este período contribuyeron a fortalecer las funcionalidades tradicionales desempeñadas por el Distrito da Sé y la Cidade Baixa, y a reorientar el crecimiento de la ciudad hacia el sur, favoreciendo la huida de los sectores medios hacia las nuevas áreas residenciales. De forma paralela, zonas como el Pelourinho se mantuvieron marginadas de estas políticas, pasando sus antiguas construcciones a ser ocupadas, casi en su totalidad, por prostitutas, artesanos y modestos comerciantes a partir de la década de $1920^{27}$.

\subsection{Segunda fase: el patrimonio como recurso para la formación de la identidad nacional brasileña}

Fue precisamente en la década de 1920 cuando algunos arquitectos brasileños, englobados en el movimiento denominado de Restauración Nacionalista, reaccionaron contra la arquitectura oficial ecléctica e impulsaron estudios sobre la arquitectura colonial brasileña, al tiempo que retomaron y reinterpretaron algunos de sus elementos constructivos y ornamentales para la proyección de nuevos edificios. Con ello buscaron las vías para la consecución de una arquitectura nacional propia, siendo durante la exposición brasileña de 1922 cuando el estilo neocolonial alcanzó su apogeo en el país. Otros arquitectos, en una búsqueda parecida, prefirieron inspirarse de forma directa en la arquitectura tradicional portuguesa, contribuyendo a la difusión en Brasil del estilo neomanuelino, o incluso en motivos ornamentales cerámicos de pueblos del Amazonas. Las contradicciones generadas en el plano arquitectónico por dicho movimiento, que no pudo finalmente romper desde el punto de vista conceptual con la noción del estilo académico tras quedar reducido a un historicismo formal, fueron criticadas en Brasil por especialistas como José Mariano, que puso de relieve la inercia oficial ante la destrucción del patrimonio y la construcción de edificios públicos con un tipo de "lenguaje plástico extraño a la tradición nacional". A pesar de ello, es cierto que los defensores de dicha corriente contribuyeron con sus investigaciones a un mayor conocimiento y valorización del patrimonio arquitectónico brasileño, siendo precisamente en estos momentos cuando se pusieron en marcha las primeras tentativas orientadas a su preservación ${ }^{28}$.

Este afán por encontrar las vías para la consecución de una arquitectura nacional inspiró incluso a los defensores del movimiento modernista en Brasil, donde, a diferencia de lo sucedido en otros países de la región, se aspiró a ser "modernos y brasileiros" más que "modernos y europeos". Para Mario de Andrade, destacado poeta, novelista, ensayista y musicólogo que, tras la Semana de Arte Moderna de São Paulo de 1922 se convirtió en la figura más representativa de dicho movimiento, ello sería posible una vez que la arquitectura modernista perdiera su anonimato e interna-

26 Leite, 2004, p. 80; Petti Pinheiro, pp. 232-245.

27 Andrade, 2004, p. 75; Mattos, 1978, p. 28; Petti Pinheiro, 2002, p. 256.

28 GutiérReZ, 1997, pp. 566-567. 
cionalismo y pasara a adoptar elementos propios de la tradición arquitectónica brasileña. Según expuso, sería entonces cuando ésta daría a Brasil "la contribución que le corresponde" 29 . En este sentido, fue especialmente la arquitectura barroca del estado de Minas Gerais la que atrajo la atención de sus componentes, que redescubrieron el barroco en sus viajes por diferentes puntos del país y percibieron la necesidad de proceder a la protección de los monumentos históricos. De forma paralela, los estados de Minas Gerais, Bahia y Pernambuco propusieron medidas legislativas para la protección de sus monumentos históricos en 1926, 1927 y 1928, respectivamente, mediante la creación de Inspetorias Estaduais de Monumentos Históricos ${ }^{30}$.

Tras la subida al poder de Getulio Vargas en 1930, los modernistas adquirieron una destacada hegemonía en el panorama intelectual nacional, en el contexto de la revolución cultural y educacional que pretendía una transformación profunda de la sociedad $^{31}$. Al mismo tiempo, la cultura popular pasó a adquirir un marcado protagonismo, a la vez que el movimiento nacionalista experimentaba un importante impulso, gracias a personalidades como Sergio Buarque de Holanda, autor de Raizes do Brazil, una de las obras fundadoras de la moderna historiografía y las ciencias sociales brasileñas. Fue éste el contexto en el que se produjeron los primeros avances importantes de cara a la protección de monumentos y objetos de valor histórico y artístico en Brasil, tras las denuncias realizadas por diferentes intelectuales sobre el estado de abandono en el que se encontraban las ciudades consideradas históricas. Entre ellos estuvo la creación en 1937 de una institución nacional de protección del patrimonio, el Serviço do Patrimônio Histórico e Artístico Nacional (SPHAN) ${ }^{32}$, subordinado al Ministerio da Educação e Saúde ${ }^{33}$. También se reglamentó la protección de los bienes muebles e inmuebles mediante el sistema del tombamento, optándose en este sentido por seguir el modelo preservacionista portugués ${ }^{34}$.

29 Ibidem, pp. 56 y 591.

30 LONDRES FonseCA, 2005, pp. 92, 93 y 95. La ineficacia de la legislación estatal llevó al diputado bahiano Jose Wanderlei de Araujo Pinho, a presentar a la Cámara Federal en 1930, un cuarto proyecto para la organización y la defensa del patrimonio histórico y artístico nacional, que no pudo ser finalmente considerado, tras producirse la disolución del Congreso Nacional como consecuencia de la revolución de octubre de dicho año. Al respecto, consultar el artículo de prensa "A defensa do patrimônio histórico e artístico do brasileiros", aparecido en el Diario da Noite, Rio de Janeiro, 15-V-1936, y "Patrimônio Histórico e Artístico", en Repertório Enciclopédico do Direito Brasileiro, vol. 36, pp. 186189. Ambos reproducidos en ANDRADE, 1987, pp. 24-25, 66-69.

31 SCHWARTZMAN, 1985, p. 165.

32 En 1946, el SPHAN cambiaría sus siglas por DPHAN (Departamento do Patrimônio Histórico e Artístico Nacional).

33 LONDRES FONSECA, 2005, pp. 81 y 239. Para más información, consultar el artículo de prensa "Como se instituiu o serviço de patrimônio histórico e artístico nacional", publicado en el Jornal do Comércio, Recife, 18-VIII-1939, reproducido en ANDRADE, 1987, pp. 30-31.

34 El sistema del tombamento consistió en el registro de bienes considerados como patrimonio de interés Histórico y Artístico en los Livros de Tombo, de los cuales se establecieron cuatro tipologías diferentes: Livro do Tombo Arqueológico, Etnográfico e Paisagístico; Livro do Tombo Histórico; Livro do Tombo Belas-Artes; Livro do Tombo das Artes Aplicadas, contando cada uno de ellos con sus respectivos volúmenes. De este proceso se derivaron obligaciones bilaterales comunes, tanto para el gobierno como para los propietarios de los bienes tombados. Para más información, consultar el decre- 
A partir de entonces, con el objetivo de reforzar la noción de ciudadanía y la cohesión nacional, monumentos identificados con la cultura dominante luso-brasileña, como iglesias coloniales, fuertes o palacios, principalmente, fueron erigidos por los agentes del SPHAN en símbolos nacionales. Dicho proceso selectivo se hizo atendiendo a cualidades constructivas, estéticas y a la vinculación mantenida por estos con hechos memorables. A pesar del interés de que el espíritu de protección de los testimonios de la historia y del arte fuera "acogido entre todas las clases" y "no apenas por una elite", los mencionados símbolos no tuvieron finalmente sentido más que para un sector muy restringido de la población. Particularmente, por la escasa circulación de bienes culturales entre la población y la opinión extendida de que Brasil no contaba con un patrimonio histórico y artístico digno de ser conservado. Esto llevaría a la existencia de un sentimiento generalizado de incomprensión con respecto a la actuación desarrollada por el SPHAN hasta la década de $1970^{35}$.

El interés despertado durante los años veinte y treinta, en determinados círculos de intelectuales y políticos del país, por el patrimonio histórico y artístico del período colonial contribuyó en buena medida a la revalorización del área central antigua de Salvador, donde varios de sus edificios testimonian el pasado esplendoroso del que fuera el principal centro urbano del Brasil en aquellos tiempos. En 1937, el ministro de Educación, Gustavo Capanema, visitó personalmente el Estado de Bahia para la recopilación de datos que fueron entregados al SPHA, comenzando a partir de entonces la conservación y la restauración del convento de San Francisco de Assis $\mathrm{y}$ de su catedral ${ }^{36}$. Anexo a esta última, la mencionada institución proyectó la apertura de un Museo Nacional de Arte Sacro, que se inauguraría a fines de la década de $1950^{37}$.

Durante este período, los intelectuales y arquitectos modernistas fueron también en Salvador los responsables de la preservación del patrimonio arquitectónico y de la realización de la arquitectura de vanguardia. Las medidas aplicadas por el SPHAN en la ciudad fueron las mismas que las dispuestas a nivel nacional, no realizando los gobiernos estatal y municipal acciones en este terreno ${ }^{38}$. La cuestión patrimonial estuvo presente en los debates y las conclusiones de la Semana de Urbanismo, celebrada en la capital bahiana en el año 1935. En su organización participó la Comissão Organizadora do Plano do Cidade, creada por el Gobierno del Estado de Bahia y la Prefeitura Municipal. En ella se pusieron de relieve los principales problemas que

to ley $\mathrm{n}^{\circ} 25,30-\mathrm{XI}-1937$, en la Web del Instituto de Patrimonio Histórico y Artístico Nacional de Brasil (IPHAN): <http://portal.iphan.gov.br/portal/baixaFcdAnexo.do?id=284> (2 de marzo de 2009).

35 LONDRES FONSECA, 2005, pp. 23, 25, 42-44 y 139. Al respecto, consultar el artículo de prensa titulado "Defesa de nosso patrimônio artístico e histórico", aparecido en O Jornal, Rio de Janeiro, X1936 y el texto de la conferencia dada en la Escola Nacional de Engenharia, titulada "O Patrimonio Historico e Artistico Nacional”, 27-IX-1939. Ambos reproducidos en ANDRADE, 1987, pp. 48-55.

${ }^{36} \mathrm{Al}$ respecto, consultar el artículo de prensa "Como se instituiu o serviço de patrimônio histórico e artístico nacional", publicado en el Jornal do Comércio, Recife, 18-VIII-1939. También, "Na casa onde se defende a nossa historia", publicado en el Correio da Manhã, Río de Janeiro, 24-I-1940. Ambos artículos se encuentran reproducidos en ANDRADE, 1987, pp. 30-31 y 36-37.

${ }^{37} \mathrm{Al}$ respecto, consultar la conferencia "O Patrimônio Histórico e Artistico Nacional” y la impartida en el Instituto Guarujá -Bertioga de São Paulo, en noviembre de 1961, titulada "O Patrimônio Histórico e Artistico Nacional”, ambas reproducidas en ANDRADE, 1987, pp. 49-55 y 57-66.

38 Diagnóstico, 2000. 
afrontaba la ciudad, como el incremento de la tuberculosis, la falta de saneamiento en las calles y las dificultades para el tránsito de vehículos o el deterioro experimentado por el patrimonio histórico y artístico. También, aspectos como la necesidad de considerar a la ciudad de forma global y de "armonizar" lo viejo con lo nuevo, siendo importante para ello que ésta no olvidara su pasado ni su patrimonio ${ }^{39}$.

Siguiendo las recomendaciones finales de dicho encuentro se organizaría en 1943 el Escritório do Plano de Urbanismo da Cidade do Salvador, entidad privada encargada de elaborar un plano director para la ciudad. Cinco años después, se aprobó el Decreto-Ley número 701, reglamentando el loteamiento, parcelamiento y uso del suelo, con un plano minucioso influido por el movimiento de ciudad-jardín, en el que se contemplaron factores económicos y sociales. Fue entonces cuando se propusieron las primeras ideas para la recuperación del patrimonio arquitectónico del Pelourinho, si bien éstas no fueron finalmente llevadas a la práctica ${ }^{40}$.

En dicha zona, los problemas de marginalidad urbana expuestos en el apartado anterior se fueron agravando a medida que sus antiguos y obsoletos edificios eran ocupados en su totalidad por prostitutas, artesanos y modestos comerciantes ${ }^{41}$. Esta situación fue plasmada por diferentes escritores de la época, en relatos como el del novelista Jorge Amado, titulado Suor, del año 1934. Al referirse al caserón número 68 de la Ladera del Pelourinho, dicho autor menciona que el mismo contaba con 116 cuartos en los que habitaban 600 personas, describiéndole como un

[...] mundo fétido, sem higiene e sem moral, con ratos, palavrões e gente. Operários, soldados, árabes de fala arrevesada, mascates ladrões, prostitutas, costureiras, carregadores, gente de todas as cores, de todos os lugares, com todos os trajes, enchiam o sobrado ${ }^{42}$.

\subsection{Tercera fase: construir una nueva Bahia "respetando su pasado"}

A partir de la década de 1950 se volvieron a emprender importantes obras de infraestructura en la ciudad, gracias, en parte, a la concentración de recursos financieros generados por la implantación de la empresa petrolera Petrobrás en el Recôncavo baiano. En esos momentos, diversos arquitectos impulsaron grandes proyectos en los alrededores del centro antiguo de Salvador ${ }^{43}$. Asimismo, se abrieron túneles y avenidas que conectaron la Cidade Alta con la Cidade Baixa, y se concedieron tierras a pequeños grupos de especuladores que pasaron a controlar el mercado inmobiliario local mediante las reformas urbanas de 196744 .

Estas intervenciones originaron mayores cambios que los experimentados a principios de siglo en la configuración de la trama original y la volumetría de zonas del

\footnotetext{
39 Penteado Filho, 1991, pp. 5-11; Petti Pinheiro, 2002, pp. 277-282.

40 Silva - Ferraz Pinheiro, 1997, p. 89.

41 Andrade, 2004, p. 75; Mattos, 1978, p. 28.

42 Batista, 2004, p. 117.

43 Diagnóstico, 2000.

44 Bittencourt AndRade, 2004. p. 45.
} 
centro tradicional de la ciudad, como el barrio del Comercio o la Rua Chile ${ }^{45}$. También contribuyeron a la pérdida de actividad en la Cidade Baixa y a agravar la situación de áreas que se encontraban ya abandonadas, como el Pelourinho. Al mismo tiempo, se redefinió el papel desempeñado por otras zonas, como la Avenida Sete de Setembro de la Cidade Alta, que de área comercial sofisticada pasó a albergar un comercio popular ${ }^{46}$. Dicho proceso se agudizó aún más con el nacimiento de nuevos centros financieros y comerciales junto a las áreas residenciales de las elites, en la franja litoral atlántica ${ }^{47}$.

Es por ello por lo que el Pelourinho se encontraba a mediados del siglo XX en un estado completo de abandono por parte de las políticas públicas. Los incendios de inmuebles se convirtieron en un problema cotidiano, al registrarse una media de 45 por año, ocasionados tanto por las precarias instalaciones eléctricas existentes, como por el interés de los propietarios en demoler los obsoletos edificios y obtener beneficios con los precios de los solares ${ }^{48}$. El geógrafo Milton Santos se refirió a los tradicionales cortiços $^{49}$ de la zona en su obra $O$ Centro da Cidade do Salvador del año 1959, describiéndolos como cubículos en los que no había ni luz, ni aire ni higiene ${ }^{50}$. Poco después, el novelista Jorge Amado, en obras como Os Pastores da Noite de 1964 o Tenda dos Milagres de 1969, recreó el Pelourinho de la época con una atmósfera mágica, a la vez que mostraba aspectos como la exclusión social, el desempleo o las estrategias de supervivencia desarrolladas por sus moradores. Caracterizó a la zona como una "universidad libre" en la que la cultura popular se manifestaba de manera espontánea, simbolizando la lucha y resistencia de un pueblo ${ }^{51}$.

De forma paralela a todo lo expuesto, tras el registro y la protección de monumentos aislados iniciados en las décadas anteriores, aparecieron en 1959 las primeras áreas protegidas en el Centro Histórico de Salvador, concretamente los distritos da Se, Passo y Conceição da Praia 52 . Pocos años después, en 1965, el DPHAN recurrió a la United Nations Educational, Scientific and Cultural Organization (UNES$\mathrm{CO}$ ), con el objetivo de ir más allá de la defensa del interés común del patrimonio frente a la incomprensión mostrada a nivel nacional por gran parte de los propietarios y de determinados sectores del poder público y de la iglesia. Con este fin se trasladó una misión de la UNESCO al Brasil, al frente de la cual estuvo el arquitecto galo Michel Parent, Inspector de Monumentos Históricos del Ministerio de Cultura francés. Entre los años 1966 y 1967 realizó un amplio inventario en la región Nordeste y desarrolló un informe final en el que puso a sus ciudades históricas y monumentos religiosos al nivel de muchas ciudades barrocas europeas, destacando a la actividad turística como la "vía natural" para la conservación de dichos complejos. Entre sus recomendaciones se encontraron algunas como la creación de una fundación pública

\footnotetext{
45 Diagnóstico, 2000.

46 Filgueiras Gomes, 2000, p. 68.

47 BitTEnCOURT ANDRADE, 2004, p. 45.

48 ZANIRATO, 2002, p. 171.

49 Cortiço: Unidad utilizada como vivienda colectiva multi-familiar. SEMPLA, 1992.

50 Bittencourt AndRade, 2004, p. 42; SAntos, 1959, p. 166.

51 Amado, 1970; Amado, 1987; Andrade, 2004, p. 78; Diniz Dos Santos, 2004, pp. 97 y 100

52 Almeida Couto, 2000, p. 96.
} 
para la gestión del área protegida, la adquisición de treinta casas en el Pelourinho para su restauración y uso comercial o la eliminación del tráfico en la zona. También se sugirió mantener el mayor número posible de habitantes y evitar la acción represiva de la policía contra sus moradores ${ }^{53}$.

Como resultado de las recomendaciones de dicha misión, el gobernador del estado de Bahia, Luis Viana Filho, creó una fundación pública para la recuperación de los barrios del Pelourinho y Maciel, la Fundacão do Patrimõnio Artístico e Cultural da Bahia, actual Instituto do Patrimônio Artistico e Cultural da Bahia (IPAC). Ésta recibió poderes para adquirir, restaurar y explotar directamente inmuebles de la zona $^{54}$. También puso en marcha un estudio socio-económico del Pelourinho, con el objetivo de valorar la posible implantación en el área de uno de los mayores centros turísticos de América del Sur. Dicho trabajo fue patrocinado por la Superintendencia de Turismo de la ciudad de Salvador y estuvo coordinado por el profesor Vivaldo da Costa Lima ${ }^{55}$. Asimismo, elaboró en 1968 una primera propuesta de recuperación del área comprendida entre el Largo del Pelourinho y el Terreiro de Jesús, incluyendo las calles Alfredo de Brito y Gregorio de Matos, pensándose que con ello se podría generar una dinámica con la que se impulsaría la recuperación del entorno circundante ${ }^{56}$. Al no concretarse finalmente la posibilidad de que organismos internacionales financiaran las medidas propuestas, el gobernador de Bahia resolvió proceder al financiamiento de las mismas con recursos nacionales ${ }^{57}$. Concretamente, las medidas aplicadas a lo largo de la década de 1970 se sufragaron con fondos del Estado de Bahia, la empresa nacional de turismo Embratur y el Programa Integrado de Reconstrução das Cidades Históricas do Nordeste $(\mathrm{PCH})^{58}$.

En 1969 comenzó el período de intervención física del Largo del Pelourinho, con la instalación de la sede de la Fundacão do Patrimõnio Artístico e Cultural da Bahia y una sucursal del Banco do Estado da Bahia, para lo cual se tuvo que desalojar a vecinos, que fueron reubicados en viviendas de barrios aledaños que contaban con peores condiciones de habitabilidad ${ }^{59}$. A comienzo de la década de 1970, dicha Fundación se asoció con la Secretaria do Planejamento (SEPLAN), la Prefeitura Municipal de Salvador y la Universidade Federal da Bahia, proponiendo conjuntamente programas de recuperación para la zona ${ }^{60}$.

En 1972, tras las intervenciones desarrolladas en el Largo del Pelourinho, se puso en marcha el Plano de Desenvolvimento Socio-Economico da Comunidade do Maciel, uno de los puntos más marginados de la zona, con el fin de contribuir a la

\footnotetext{
53 Ormindo de Azevedo, 2004, p. 45; Duarte Bomfim, 1994, p. 46; Mattos, 1978, p. 151.

54 ZANIRATO, 2004, pp. 327 y 328.

55 MATTOS, 1978, p. 151.

56 Silva - Ferraz PinHeIro, 1997, p. 90.

57 Mattos, 1978, p.153.

58 Ormindo DE AzEVEdo, 2004, p. 46. El PCH, dependiente de los Ministerios de Planificación y de Educación y Cultura, fue creado en 1973 e incorporado al IPHAN en 1979. Para más información, consultar la Web del Ministerio da Cultura de Brasil: www.monumenta.gov.br/site/?page_id=165 (10 de marzo de 2009)

59 DuARTE Bomfim, 1994, p. 51.

60 ZANIRATO, 2002, pp. 172 y 173.
} 
mejora de las condiciones de vida de sus habitantes y a la restauración de inmuebles. Junto a la recuperación de determinados edificios, se comenzó a trabajar con el Programa de Alfabetización del Gobierno Federal (Mobral), instalándose, entre otras cosas, una escuela de tipografía, patrocinada por la Fundación Calouste Gulbenkian de Portugal, y una tienda para la venta y la divulgación de la artesanía producida por el vecindario ${ }^{61}$.

Todas las medidas adoptadas por entonces en el centro histórico formaron parte de las actuaciones de remodelación de la capital bahiana del gobernador Antônio Carlos Magalhães, en el poder entre 1971 y 1975. Éstas incluyeron la creación de nuevos centros de carácter administrativo, de servicios e industriales en la periferia urbana, todos ellos articulados a través de una nueva red de vías rápidas. La privatización de tierras públicas, llevada a cabo a comienzos de los años setenta en el suelo urbano de Salvador, propició la práctica de este tipo de medidas, al abrirse con ello nuevas áreas de expansión urbana. No obstante, pese a las intenciones del citado Gobernador de "construir una nueva Bahia sin destruir su pasado", la ausencia de un plan maestro y la ejecución de dichas actuaciones de manera desarticulada, contribuyeron a marginar aún más el centro histórico ${ }^{62}$.

En 1976, bajo la gestión del gobernador Roberto Santos, se adquirió el Solar Ferrão de la calle Gregório de Matos, edificio colonial de los siglos XVII y XVIII, y se procedió a su restauración con fondos del gobierno estatal y del ya citado Programa Integrado de Reconstrução das Cidades Históricas do Nordeste. Ese mismo año se creó el Taller de Restauración de Obras de Arte, que puso en marcha iniciativas orientadas a la formación de vecinos reclutados por el Programa de Desenvolvimento Sócio-Econômico do Maciel en técnicas de restauración, con el objetivo de incluirles en los programas de actuaciones previstos en el centro histórico $^{63}$. A partir de ese año y hasta 1979, el IPAC desalojó a los inquilinos de algunos inmuebles de la zona intervenida, que fueron restaurados y destinados a alojar una comisaría, escuelas y guarderías. Este proceso incentivó una pérdida del peso de la función residencial en la zona y que numerosos propietarios abandonaran sus inmuebles con la esperanza de que fuesen finalmente adquiridos por el Estado. El IPAC adaptó, de manera paralela, edificios concretos en los alrededores, con el objetivo de alojar a las personas desplazadas, conformando habitaciones plurifamiliares con un único sanitario por planta y cocina colectiva. En 1977 elaboró un plan, junto con el Ministerio de Transporte, destinado a la implantación de áreas de estacionamiento, la peatonalización de algunas calles del Pelourinho y la organización de un horario para carga y descarga ${ }^{64}$.

Las medidas aplicadas durante los años setenta tuvieron, por lo general, un limitado alcance. En el plano social, hacia 1980 persistía una clase media empobrecida en la zona de Colina del Carmo, que por el clima de inseguridad existente ansiaba

61 Almeida Couto, 2000, p. 100.

62 En este sentido, Paulo Ormindo de Azevedo afirma que "el gran error fue imaginar el Pelourinho como un centro turístico en medio de un área muy deprimida, sin articulaciones con los nuevos centros especializados". Ormindo DE AzeVedo, 2004, p. 47; FilgueIras Gomes, 2000, p. 68.

63 Almeida Couto, 2000, p. 100.

64 ZANIRATO, 2002, p. 173. 
trasladarse a otras zonas de la ciudad. En áreas como la de Maciel vivían poco más de 1.800 personas, la mayor parte de ellas contaban con 28 años o menos (66\%), procedían del interior $(61 \%)$ y habitaban en calidad de inquilinos en inmuebles con pésimo estado de conservación y, por lo general, con servicios higiénicos de uso colectivo. Dentro de dicha población, dos tercios de la económicamente activa no poseían un trabajo estable y eran subempleados o desempleados, siendo relevante el número de personas que se dedicaban a la prostitución (un 13\% de la población trabajadora) ${ }^{65}$. Esta situación se explica, en parte, por factores como la falta en la política brasileña de instrumentos de conservación que facilitaran la intervención en conjuntos urbanísticos con función de vivienda, al orientarse más a la protección de monumentos aislados de propiedad y/o usos públicos. También, por el escaso atractivo que la zona tenía para los inversores privados, dadas las limitaciones legales sobre los bienes declarados como patrimonio histórico, y la existencia de alternativas más seguras y lucrativas en las nuevas áreas de expansión de la ciudad ${ }^{66}$.

En el año 1983 comenzaron a desarrollarse los estudios encaminados a elevar el Centro Histórico de Salvador a la condición de Patrimonio de la Humanidad. En esos momentos, el Internacional Council on Monuments and Sites (ICOMOS) realizó un reconocimiento de la labor desarrollada en Salvador para preservar esa zona frente a las amenazas de un crecimiento urbano acelerado ${ }^{67}$. Fue a partir de dicho año, precisamente, cuando el Municipio de Salvador, con base en los estudios del Plano Director de Desenvolvimento Urbano, reconoció a través de la ley $\mathrm{n}^{\mathrm{o}} 3.289 / 83$ la figura de centro histórico como un área sujeta a tratamiento especial. En 1985 se produjo su declaratoria como Patrimonio Mundial, siendo por entonces cuando el nuevo gobierno municipal electo, opositor al estatal, reivindicó la gestión integral del centro histórico como espacio visto como "una nueva frontera potencial de inversiones externas". Esta situación contribuyó a crear choques de intereses entre los diferentes actores involucrados en la cuestión patrimonial de ámbito nacional (SPHAN), estatal (IPAC), y local (la Prefeitura).

El mayor protagonismo adquirido por el gobierno local en este terreno se reflejó, entre otros aspectos, en la puesta en marcha por parte de la Prefeitura de diferentes iniciativas para la recuperación del centro histórico. Entre ellas, la creación en 1986 del Programa Especial de Recuperação e Revitalização dos Sitios Históricos de Salvador (PERSH), vinculado a la recién creada Fundação Gregório de Mattos (FGM) y la institución de los tres Sitios Históricos de Salvador (Centro, Itagagipe y Rio Vermelho). Poco después, en la conformación del Parque Histórico del Pelourinho (PHP) en la parte más central del área protegida, conformado por 42 manzanas y cerca de 1000 edificios. Con ello se procedió a la delimitación de un área prioritaria de intervención para el desarrollo de obras de emergencia y reciclaje de algunos edificios de uso mixto ${ }^{68}$.

65 DuARTe BomfiM, 2000.

66 Filgueiras Gomes, 2000, p. 69.

67 UNESCO, World Heritage, Historic Centre of Salvador de Bahia. En línea: $<$ http://whc.unesco.org/en/list/309> (13 de noviembre de 2006).

68 ZANIRATO, 2002, p. 174. 
No obstante, durante los años ochenta hubo una ausencia casi total de intervenciones en la zona del Pelourinho y Maciel, circunstancia que acentuó el proceso de deterioro de sus inmuebles e incrementó los niveles de pobreza ${ }^{69}$. De forma paralela, fue destacable para esos momentos la proliferación de blocos afro o grupos musicales en el Pelourinho, integrados principalmente por negros y mulatos. Algunos, como el de Olodum, pusieron en marcha una política cultural relacionada con la lucha contra la discriminación racial y el impulso a la autoestima y el orgullo de ser afro-brasileño. Con ello, contribuyeron a la divulgación y la afirmación de dicha zona como barrio negro o "quilombo urbano"70, al tiempo que muchos continuaron viendo al Pelourinho como un lugar marginal y peligroso.

\subsection{Cuarta fase: el turismo como motor para el cambio}

Durante la década de 1990, el Gobierno Estatal, a través del IPAC y la Companhia de Desenvolvimento da Região Metropolitana de Salvador (CONDER), puso en marcha el proyecto más ambicioso orientado a la recuperación del Centro Histórico de Salvador. Esta iniciativa estuvo liderada por el gobernador de Bahia Antônio Carlos Magalhâes, uno de los principales líderes políticos de Brasil, que durante el transcurso de su campaña había puesto de manifiesto que la prioridad de su administración sería el desarrollo del turismo como recurso para el crecimiento económico de la región ${ }^{71}$. Tras su victoria, el Gobierno del Estado de Bahia asumió de manera íntegra las tareas de manutención y conservación de las áreas intervenidas, convirtiéndose en el mayor inversor en el proceso de recuperación del centro histórico.

Tras la promulgación de la Constitución brasileña de 1988 se crearon nuevas posibilidades para la protección de bienes culturales en el país con la previsión de nuevos instrumentos legales, circunstancia que fue aprovechada por un grupo de técnicos del IPAC para crear ese mismo año un anteproyecto de legislación estatal ${ }^{72}$. En julio de 1992, el Gobierno del Estado de Bahia puso en marcha la primera etapa del Programa de Recuperación del Centro Histórico de Salvador, interviniéndose durante las primeras cuatro un total de 356 inmuebles o el equivalente a 104 mil metros cuadrados. A lo largo de la quinta etapa fueron intervenidos 63 edificios en dos manzanas y se puso en marcha el mayor trabajo de restauración llevado a cabo en Brasil, el de la Catedral Basílica. También se emprendieron obras para la recuperación del Convento e Iglesia de São Francisco y se llevó a cabo la construcción de un nuevo estacionamiento con capacidad para doscientos vehículos. La sexta etapa abarcó dos manzanas, siendo entonces cuando se procedió a la creación del Quarteirão Cultural, con cine y teatro.

En lo que respecta a las técnicas empleadas en la restauración de edificios, los trabajos se centraron en la mejora de los cimientos, las estructuras y las coberturas,

\footnotetext{
69 Almeida Couto, 2000, p. 102.

70 Filgueiras Gomes, 2000, pp. 70 y 71.

71 Fernandes Araujo, 1998, pp. 42-44; Zanirato, 2004, p. 329.

72 Diagnóstico, 2000.
} 
adoptándose para estas últimas una innovadora solución de insertar un sobreforro de fibra de vidrio con el objetivo de impedir las filtraciones. Asimismo, se emplearon tejas de fabricación industrial, dados los problemas de conservación presentados por las de tejas de barro artesanales. Para la restauración de las fachadas se emprendieron investigaciones históricas y prospecciones estratigráficas, con el fin de determinar las tonalidades de los colores característicos de la zona. Únicamente para monumentos construidos durante el siglo XVII y la primera mitad del siglo XVIII se procedió a la aplicación del tono blanco tradicional del período ${ }^{73}$.

Las intervenciones desarrolladas, al tiempo que fueron aplaudidas por UNES$\mathrm{CO}^{74}$, recibieron también numerosas críticas por producir en la práctica una "idealización de la arquitectura antigua", como consecuencia del fortalecimiento de las características coloniales de aquellos inmuebles que sufrieron alteraciones durante los siglos XIX y XX, o por el uso de una paleta de colores en las fachadas restauradas, que no siempre se corresponden con la tradición arquitectónica del lugar. También por la destrucción ocasionada en el "pulmón" de algunas de las manzanas para la creación de nuevos espacios a modo de "plaza central o shopping mall", en los que realizar espectáculos musicales ${ }^{75}$.

Uno de los aspectos más controvertidos fue el de la expulsión de la población residente en la zona, al considerar los gestores públicos y expertos del momento incompatible el mantenimiento de los habitantes con la preservación del patrimonio. Para ello, argumentaban que estos no podrían hacer frente a los elevados costes de mantenimiento de los inmuebles restaurados, y existía el temor de que pudieran proceder al desvalijamiento de elementos arquitectónicos de valor para su venta ${ }^{76}$. Con el objetivo de negociar las condiciones en las que los pobladores debían desalojar sus viviendas, primero se llevó a cabo un catastro sobre sus habitantes, comerciantes y otros usuarios, y, posteriormente, se les convocó a través del Servicio Social del Programa. Entre las posibles opciones que les fueron ofertadas estuvieron, tanto la indemnización en metálico por mudarse, como la recolocación definitiva en un inmueble recuperado, pagando alquiler con contrato jurídico válido, o la recolocación provisoria en un inmueble hasta que finalmente fuera factible el traslado a una vivienda especialmente adaptada. Como forma de rentabilizar las inversiones, el Gobierno Estatal estableció que en aquellos casos en los que un propietario contara con dos inmuebles en la zona, uno le sería devuelto restaurado y el otro a cambio quedaría en manos del Estado. En caso de que tuviera uno sólo, éste debía ceder su posesión en "comandato"77 por un período de diez años, momento a partir del cual le sería devuelto. De no ser posible establecer algún tipo de acuerdo, se procedería a la expropiación ${ }^{78}$.

73 Almeida Couto, 2000, pp. 114-119.

74 Duarte Bomfim, 2000.

75 Filgueiras Gomes, 2000, p. 74.

76 DuARTE BOMFIM, 1994.

77 Comandato: Contrato por el cual se da o recibe prestada una cosa de las que pueden usarse sin destruirse, con la obligación de restituirla.

78 Almeida Couto, 2000, pp. 107 y 110. 
Las indemnizaciones fueron calculadas según cada caso, dependiendo del tiempo de residencia en la zona, el tamaño de las familias o la situación jurídica de la ocupación. Según se menciona en el tomo que la Série Patrimônios Mundiais do Brasil dedica a Salvador, un $85 \%$ de los indemnizados pudieron comprar con las cantidades recibidas casas populares, tanto en las áreas vecinas al área intervenida como en otros barrios proletarios de la ciudad y su periferia, pasando con ello de la condición de inquilino o "invasor" a la de propietario ${ }^{79}$. No obstante, autores como Silvia Helena Zanirato ponen de relieve que los criterios adoptados para el cálculo de las indemnizaciones buscaron proteger, principalmente, los intereses del gobierno, evitando que tuviera que pagar elevadas cantidades. $Y$ es que una parte minoritaria de los habitantes del Pelourinho cumplía entonces alguno de los requisitos más valorados para el cobro de indemnizaciones, fijadas entre 3 y 6 millones de cruzeiros, o lo que es lo mismo, entre 5 y 10 veces el salario mínimo por entonces vigente. Entre ellos se encontraban algunos como el de estar casado, tener el grado de escolaridad completo, poseer un empleo "regular", ser inquilino y contar con buenas infraestructuras en las viviendas ${ }^{80}$.

Una parte importante de los que pudieron reclamar indemnizaciones terminaron por aceptarlas, al suponer cantidades relativamente significativas para una población que se encontraba prácticamente desposeída. Con todo, un grupo de los indemnizados se unieron pronto formando el Movimento de Defesa dos Favelados, con el objetivo de reivindicar al IPAC indemnizaciones más justas, teniendo en cuenta el proceso inflacionario vivido por esos años en Brasil y la imposibilidad de poder adquirir una vivienda con lo recibido. Estos también pusieron de relieve, la violencia empleada por dicho instituto a la hora de desalojar algunos de los inmuebles intervenidos ${ }^{81}$.

Finalmente, sólo un 5\% de la población pudo regresar a sus viviendas en el Pelourinho, concretamente los que, según el IPAC, desempeñaban actividades consideradas compatibles con el desarrollo de la actividad turística contemplada para la zona y la preservación de los inmuebles, que generaban empleo y atraían consumidores. Este criterio fue discutido por algunos de los antiguos pobladores, que pusieron de relieve que el Pelourinho, durante las décadas en las que el gobierno se había olvidado de la zona, había constituido ya un punto de atracción turística, siendo su población precisamente la que había contribuido a la preservación de gran parte de sus edificios ${ }^{82}$. Para autores como Marco Aurelio A. de Figueiras Gomes, hubiera sido posible desarrollar la actividad turística y reforzar la actividad cultural en el Pelourinho sin necesidad de haber expulsado a sus residentes, puesto que a principios de la década de 1990 existían en la zona numerosos caserones deshabitados. Esto hubiera facilitado que el barrio mantuviese su vida propia y la riqueza cultural de sus vecinos ${ }^{83}$.

Las antiguas construcciones concebidas como viviendas pasaron a ser ocupadas tras su rehabilitación por bares, restaurantes, tiendas, galerías de arte o museos, en su

\footnotetext{
${ }^{79}$ Ibidem, p. 107.

80 ZANIRATO, 2004, pp. 332 y 333.

81 Ibidem, pp. 337 y 339.

82 Ibidem, pp. 334, 336 y 337.

83 Filgueiras Gomes, 2000, p. 75.
} 
mayor parte orientados al sector turístico. Por lo general ocupan los niveles bajos de los edificios, permaneciendo todavía gran parte de los pisos superiores desocupados. Este hecho, unido a la existencia de un elevado número de inmuebles completamente vacíos, supone un grave riesgo para la preservación del patrimonio inmueble ${ }^{84}$. Dicha situación ha obligado al Estado a tener que invertir ingentes recursos en el mantenimiento de la zona ya intervenida, que podrían haberse destinado a la recuperación de zonas aledañas al Pelourinho que presentan un lamentable estado de conservación.

Desde el punto de vista del patrimonio inmaterial, el programa del Gobierno Estatal puesto en marcha durante la década de 1990 para la recuperación del Pelourinho ocasionó importantes transformaciones en la zona. La expulsión del 95\% de su población supuso la pérdida de numerosas manifestaciones culturales que se daban allí de manera espontánea. Este aspecto resulta llamativo, dado que los líderes políticos del estado eran conscientes de la importancia que la cultura negra tenía de cara a la promoción del turismo en Salvador. Es más, la industria turística adoptó durante esos momentos la imagen por entonces existente de "territorio negro" vinculada al Pelourinho, diferente de la que durante los años sesenta y setenta había concebido a la zona como "lugar de residencia de las antiguas élites blancas de Bahia"85.

En este sentido, se optó por poner en marcha tanto programas de incentivo fiscal a la cultura para la producción de espectáculos, como la inversión de ingentes recursos en el desarrollo de programas de animación sociocultural, todo ello en el marco de las medidas orientadas al desarrollo del turismo en el Centro Histórico de Salvador. En ellas se incluyó la presencia, más visible que en otros puntos de la ciudad, de un cuerpo de policía especializado para turistas que, con el objetivo de proteger a los visitantes de posibles asaltos, llegaron a controlar el acceso de personas desde zonas aledañas al Pelourinho, concretamente desde la Baixa dos Sapateiros o la Rua 28 de Setembro ${ }^{86}$.

El financiamiento de las intervenciones descritas se hizo, en su mayor parte, a fondo perdido por parte del gobierno del Estado de Bahia, al no mostrar el sector privado especial interés por invertir en la zona. Entre ellos, los empresarios del sector turístico que prefieren invertir sus capitales en la zona costera de la ciudad, lugar que concentra los principales hoteles y restaurantes ${ }^{87}$. Por otra parte, el turismo no ha aportado al Estado los recursos económicos necesarios para hacer frente al total de los gastos generados por las medidas descritas, en parte por el carácter estacional que dicha actividad tiene en Salvador (enero/ comienzos de marzo y julio/agosto) ${ }^{88}$.

Con el objetivo de paliar la extrema dependencia del Estado y asegurar la sostenibilidad social y económica del proyecto, las autoridades fomentaron la creación de nuevas líneas de financiamiento, tanto internas como externas, a cargo de instituciones como la Caixa Econômica Federal o el proyecto Monumenta-BID. También se

84 Diagnóstico, 2000.

85 Filgueiras Gomes, 2000, pp. 72 y 73.

86 ZANiRATo, 2002, p. 164. Este hecho pudimos comprobarlo, de forma directa, durante una visita realizada al Pelourinho en el año 2004.

87 ORMINDO DE AZEVEDo, 2004, p. 50.

88 Filgueiras Gomes, 2000, p. 76. 
implicó de manera más activa en la gestión del proceso a la Prefeitura Municipal, con proyectos como el de Polígono da Identidade ${ }^{89}$, y al Instituto do Patrimônio Histórico e Artístico Nacional (IPHAN), que ha centrado su tarea en la realización de obras de emergencia en monumentos protegidos, y la supervisión, aprobación y fiscalización de proyectos ${ }^{90}$.

Por otro lado, dichas autoridades permitieron que el costoso programa de animación cultural popular que desarrolla el gobierno en la zona fuera disfrutado por expobladores y vecinos de baja renta, produciéndose con ello una "reapropiación virtual" reciente del barrio por estos grupos. En este sentido, las autoridades han cambiado la concepción original dada al proyecto en este punto, concibiéndolo ahora como forma de esparcimiento popular que anima el barrio y como un posible recurso para el incremento de votos en las elecciones, al tiempo que han aceptado también el uso habitacional como vía para la rehabilitación del barrio. Para ello, se han puesto en marcha algunas iniciativas, como la del proyecto Rememorar que, coordinado por la Secretaria de Desenvolvimento Urbano del Gobierno de Bahia (SEDUR), en conjunto con la Prefeitura de Salvador y con el apoyo de la Caixa Econômica Federal, contempla la recuperación de caserones de los siglos XVII y XVIII para la construcción de apartamentos de dos habitaciones. En principio, las unidades habitacionales son financiadas para funcionarios públicos del Estado y adquiridas a través de un sistema de arrendamiento, con un plazo de quince años para proceder al pago de las mismas. No obstante, estas medidas se orientan a un público de ingresos superiores a los de los antiguos pobladores de la zona, e implican la evacuación de algunos de los escasos inquilinos existentes en las áreas intervenidas, a cambio de pequeñas indemnizaciones u ofreciéndoseles viviendas en alquiler ${ }^{91}$. Mientras tanto, parte de la población que fue expulsada del Pelourinho continúa reclamando su derecho a regresar.

Por último, cabe destacar también entre los asuntos pendientes la concreción de medidas para la mejora de los accesos al Centro Histórico. De hecho, el Plan Integral de Transportes de Salvador, que comprende la reorganización del sistema de autobuses urbanos y la implantación del Metro, no contempla la inclusión de dicha zona $^{92}$, siendo éste un factor vital que potenciaría la dinamización del área con el desarrollo de nuevas funcionalidades, como propuso el Relatório Final del IV Encontro Sirchal ${ }^{93}$.

\section{REFLEXIONES FINALES}

En el presente trabajo hemos analizado los diferentes procesos de intervención que ha experimentado el Centro Histórico de Salvador desde fines del siglo XIX hasta la actualidad. De todo lo expuesto destacamos algunos aspectos:

${ }^{89}$ El proyecto Polígono da Identidade se orienta a la recuperación y renovación de corredores y espacios públicos de gran valor referencial en la zona. DiAGNóstico, 2000.

90 Página web del IPHAN: <http://www.iphan.gov.br/> (21 de junio de 2007).

91 ORMINDO DE AZEVEDo, 2004, p. 51.

92 Para más información, consultar la Web de Metrô Salvador [en línea] <http://www.metro.salvador.ba.gov.br/> (21 de noviembre de 2008).

93 Diagnóstico, 2000. 
La existencia en el mismo de zonas que han experimentado violentas transformaciones, en nombre de un malentendido concepto de modernidad, frente a otras que, abandonadas durante décadas por la administración, sufrieron un importante deterioro.

Las políticas de mayor alcance han sido lideradas por determinadas personalidades relevantes del ámbito político local o regional, que han pretendido con ellas incrementar su prestigio. El marketing político, por ello, ha desempeñado un papel importante en el proceso analizado.

Desde fines del siglo XIX, estas iniciativas han sido justificadas con diferentes argumentos y motivaciones. Entre ellas, el deseo de otorgar una imagen más "civilizada" y europea de Salvador, contribuir al refuerzo de la noción de ciudadanía y la cohesión nacional, modernizar la ciudad o dinamizar la economía local y regional con el desarrollo de la actividad turística. En ninguno de los casos las autoridades han tenido prácticamente en cuenta las demandas existentes en la población local.

Bahia cuenta con un número importante de instituciones, especialistas, leyes y documentos vinculados a la gestión del patrimonio material e inmaterial. No obstante, esto no impide que en la práctica se sigan aplicando medidas que continúan atentando contra la integridad del Centro Histórico de Salvador.

El escaso interés de la iniciativa privada por invertir en zonas como la del Pelourinho ha puesto en riesgo el sostenimiento económico de los proyectos desarrollados por las autoridades en la zona. Al mismo tiempo, el escaso interés de multinacionales y sectores altos de la sociedad bahiana por participar en la apertura de negocios o compra de viviendas, ha permitido que no se observen los efectos negativos derivados de procesos como los de "mercantilización multinacional homogeneizadora" o "gentrificación".

Los efectos de la mayor parte de las políticas aplicadas en el Centro Histórico de Salvador y sus alrededores han terminado por marginar dicha área frente a las nuevas centralidades urbanas conformadas en otros puntos de la ciudad, especialmente en el litoral.

El Pelourinho ha despertado diferentes imaginarios entre la población de Salvador. Lugar de residencia de las antiguas élites blancas bahianas, espacio "marginado" y conflictivo o "centro de la cultura afro-brasileña" serían los más importantes. En este sentido, las campañas de marketing turístico, concibiendo a la historia como mero producto de entretenimiento, refuerzan la imagen de la zona como centro de la cultura afro-brasileña de forma algo caricaturizada.

Entre los principales logros alcanzados hasta la fecha se encuentra la recuperación del patrimonio material del Pelourinho, si bien la metodología empleada para ello ha sido criticada por algunos especialistas en la materia. También la puesta en marcha de un continuo programa de actividades culturales y de ocio que, más recientemente, involucra tanto a la población local como a turistas. Con ello, se está contribuyendo a la valorización y difusión del riquísimo patrimonio inmaterial que posee la ciudad.

Del proceso descrito podría deducirse, por tanto, la necesidad de proyectar una nueva etapa en la gestión del Centro Histórico de Salvador que contemple la zona en relación al conjunto urbano en el que se inserta, mejorando los accesos y buscando un equilibrio con otras de las centralidades existentes en la ciudad. También que con- 
trarreste el impacto de la actividad turística con el desarrollo de otras funcionalidades, especialmente la residencial. Todo ello debería verse acompañado de una participación efectiva de los ciudadanos en la planificación urbana, y de políticas educativas que contribuyan a que los habitantes de Salvador valoren su rico legado patrimonial. Se trata, en definitiva, de encontrar un equilibrio entre los intereses de los políticos, los académicos y las comunidades implicadas, consiguiendo que la iniciativa privada desempeñe un papel destacado en la gestión urbana, bajo la tutela de los poderes públicos.

\section{REFERENCIAS BIBLIOGRÁFICAS}

Almeida Couto, Adriana [et. al.]

2000 Centro Histórico de Salvador, Bahia: patrimonio mundial. São Paulo. Horizonte Geográfico.

AMADO, Jorge

1970 Tenda dos milagros. São Paulo. Martins.

1987 Os pastores da noite. Rio de Janeiro - São Paulo. Record.

ANDRADE, Lílian

2004 "Os Pastores da Noite - um diálogo entre a geografia, a literatura e o cinema na obra de Jorge Amado". En Ferraz PinheIro - Da Silva (org.), pp. 71-81.

ANDRADE, Rodrigo Melo Franco de

1987 Rodrigo e o SPHAN: coletânea de textos sobre patrimônio cultural. Rio de Janeiro. Fundação Nacional Pró-Memoria.

Batista, Selma Paula

2004 "A literatura como instrumento de análise para a compreensão do espaço urbano de Salvador." En Ferraz Pinheiro - Da Silva (org.), pp. 115-121.

BitTENCOURT ANDRADE, Adriano

2004 "A cidade de Salvador, dos idos de 1959: os olhares de Jorge Amado e Milton Santos". En Ferraz PinheIro - Da SiLVA (org.), pp. 31-48.

Diagnóstico

2000 Diagnóstico. IV Encontro Sirchal. Salvador. Sirchal. En línea: http://www.archi.fr/SIRCHAL/seminair/sirchal4/frameDiagVFR.htm.

Diniz Dos SANTOS, Jânio Roberto

2004 "Geografia e literatura nas obras de Milton Santos e Jorge Amado: o estudo da cidade de Salvador". En Ferraz Pinheiro - Da Silva (org.), pp. 95-104.

DUARTE BOMFIM, Juarez

1994 Politicas Públicas para o Centro Histórico de Salvador: o Caso do Parque Histórico do Pelourinho. Investigação de Originalidade Numa Ação de Governo Local. Salvador. Escola de Administração/Universidad Federal de Bahia Disertación de Maestría. 
2000 "Innovación y renovación urbana. El caso del Centro Histórico de Salvador - Bahia en Brasil". Scripta Nova, revista electrónica de Geografía y Ciencias Sociales de la Universidad de Barcelona. Barcelona. $n^{0} 69$ (67). En línea: <http://www.ub.es/geocrit/sn-6967.htm>.

Fernández, Ana - Filgueiras Gomes, Marco Aurélio A. de (orgs.)

1992 "Idealizações urbanas e a construção de Salvador moderna: 18501920". En Cidade \& história: modernização das cidades brasileiras nos séculos XIX e XX. Salvador. MAU/FAUFBA - ANPUR, pp. 92-103.

FERNÁNDEZ ARAuJo, Antonio Sergio

1998 Empresarialismo urbano em Salvador: a recuperação do Centro Historico Pelourinho. Recife. Universidade Federal de Pernambuco. Disertación de Maestria.

Ferraz Pinheiro, Délio José - Da Silva, Maria Auxiliadora (orgs.)

2004 Visões imaginárias da cidade da Bahia.Um diálogo entre a geografia e a literatura. Salvador. EDUFBA/Mestrado em Geografia.

Filgueiras Gomes, Marco Aurelio

2000 "Historia, cultura y turismo en la ciudad contemporánea: algunas reflexiones sobre la rehabilitación del Pelourinho". Revista Medio Ambiente y Urbanización. Buenos Aires. $\mathrm{n}^{\circ}$ 55, pp. 66-78.

Goulart ReIs, Nestor

2001 Imagens de vilas e cidades do Brasil Colonial. San Pablo. Editora da Universidade de São Paulo - Impresa Oficial do Estado.

GUTIÉRREZ, Ramón

1997 Arquitectura y Urbanismo en Iberoamérica. $3^{\text {a }}$ edición. Madrid. Cátedra.

HARVEY, David

2007 Espacios del capital. Hacia una geografía crítica. Madrid. Akal.

LEITE, Rogério Proença

2004 Contra-usos da Cidade. Lugares e espaço público na experiência urbana contemporânea. Campinas. Editora de Unicamp.

LONDRES FonseCA, Maria Cecília

2005 O Patrimônio em Processo. Trajetória da política federal de preservação no Brasil. $2^{\mathrm{a}}$ edición. Rio de Janeiro. Editora UFRJ - MinC - Iphan.

LuQue AZConA, Emilio - SMith, Harry

2007 "Novedades y retos en la gestión de centros históricos de Europa, Latinoamérica y el Caribe (1980-2005)". Scripta Nova, revista electrónica de Geografía y Ciencias Sociales de la Universidad de Barcelona. Barcelona. vol. XI. $\mathrm{n}^{\mathrm{o}} 254$.

MANDER, Jerry - GoldSMITH, Edward (eds.)

1996 The case against the Global Economy and for a turn toward the Local. San Francisco. Sierra Club Books.

Mattos, Waldemar

1978 Evolução histórica e cultural do Pelourinho. Rio de Janeiro. Editora Gráfica Barbero. 
OLsEWSKI Filha, Sofía

1989 A fotografia e o negro na cidade do Salvador. Salvador. EGBA Fundação Cultural do Estado da Bahia.

ORMINDO DE AZEVEDO, Paulo

2004 "El Pelourinho de Bahia, cuatro décadas después". ICONOS. Quito. n 20, pp. 45-52.

Penteado Filho, Paulo de Arruda

1991 "Planejamento Urbano em Salvador". Veracidade. Salvador. vol. 1. n 2, pp. 5-11.

PetTi Pinheiro, Eloísa

2002 Europa, França e Bahia: difusão e adaptacão de modelos urbanos. Salvador. EDUFBA.

RoMERO, José Luis

1986 Latinoamérica: las ciudades y las ideas. $6^{\mathrm{a}}$ edición. Buenos Aires. Siglo XXI editores.

RuY, Affonso

1978 A primeira revolução social brasileira (1798). San Pablo. Ed. Nacional. SANTOS, Milton

1959 Centro da Cidade do Salvador. Estudo de Geografia Urbana. Salvador. Publicações da Universidade da Bahia.

Sargatal Bataller, Ma. Alba

2000 "El estudio de la gentrificación”. Scripta Nova. Revista Electrónica de Geografía y Ciencias Sociales. Barcelona, $\mathrm{n}^{\mathrm{o}}$ 228. En línea: www.ub.es/geocrit/sn-94-66.htm

SCHWARTZMAN, Simon

1985 "Gustavo Capanema e a educação brasileira: uma interpretação". Revista Brasileira de Estudos Pedagógicos. Brasília. no 66 (153), pp. 165-172.

SEGAWA, Hugo

2000 Prelúdio da Metrópole. Arquitectura e urbanismo em São Paulo na passagem do século XIX ao XX. San Pablo. Ateliê Editorial.

SEMPLA (Secretaria Municipal do Planejamento)

1992 Coletânea de documentos; instrumentos urbanísticos, leis e decretos. São Paulo. http://cortico.pcc.usp.br/html/Tese.html.

SiLva, Maria Auxiliadora da - Ferraz PinHeIro, Delio José

1997 "De picota a ágora: las transformaciones del Pelourinho". Anales de Geografia de la Universidad Complutense. Madrid. n 7, pp. 69-97.

TAVARES, Luís Henrique

1987 História da Bahia. $8^{\mathrm{a}}$ edición. San Pablo. Ática.

Troitiño VinUESA, Miguel Angel (ed.)

2009 Ciudades Patrimonio de la Humanidad: Patrimonio, Turismo y Recuperación Urbana. Sevilla. Universidad Internacional de Andalucía/Junta de Andalucía. 
ZANIRATO, Silvia Helena

2002 "As politicas de preservação e de usufruto do Patrimônio Cultural: o Centro Histórico de Salvador, como um estudo de caso". Pós- história. Revista de posgraduação em História. Assis. San Pablo. no 10, pp. 161-180.

2004 "A restauração do Largo do Pelourinho: edificações tão bonitas de se ver, histórias não tão bonitas de se contar". Dimensões. Revista de História da UFES. Vitória. n 16, pp. 323-344. 